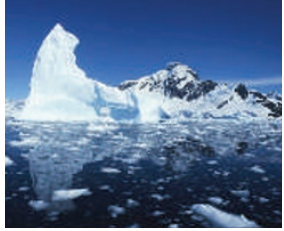

POLAR RESEARCH

Get International Polar Year started with science from the ends of the Earth. www.nature.com/news/ infocus/polarresearch. html

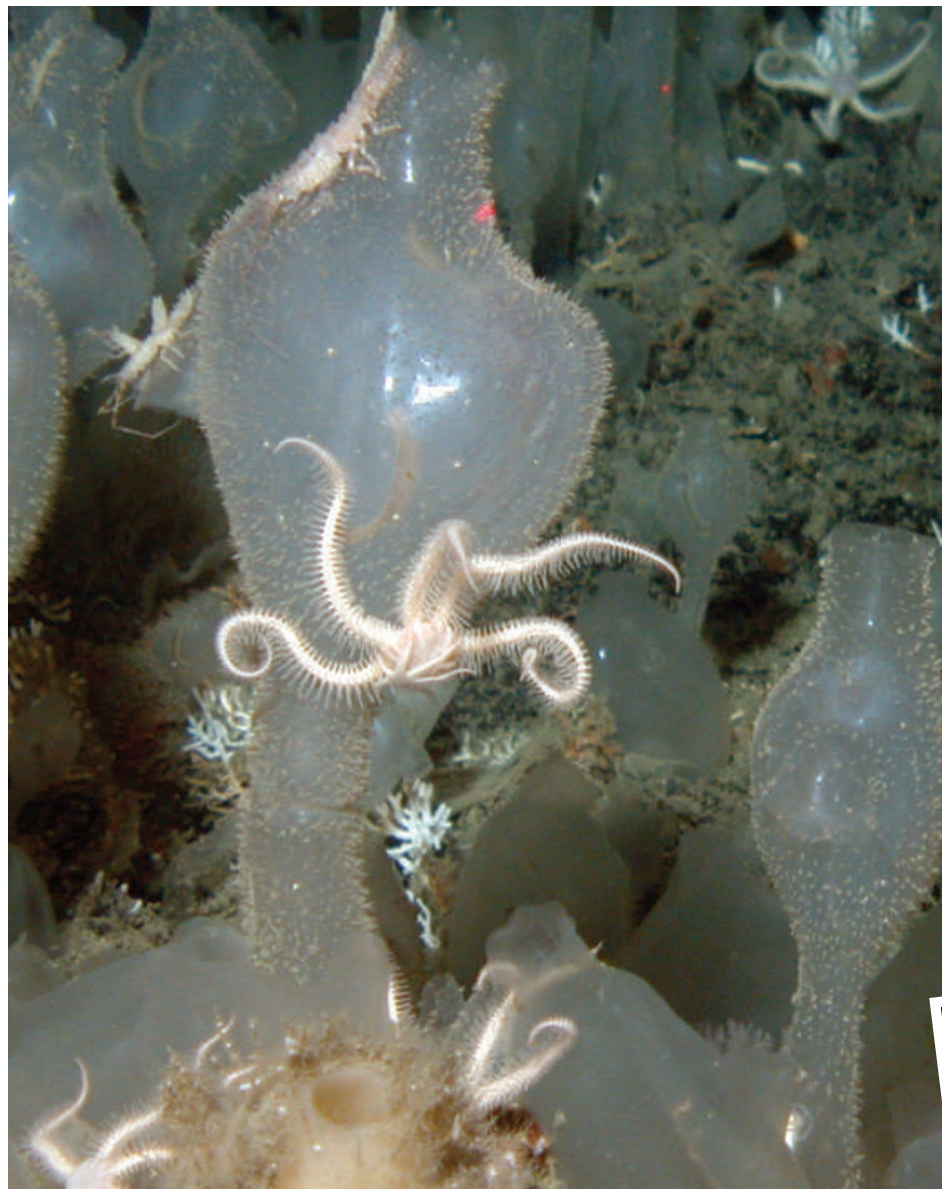

\section{Letting the light in on Antarctic ecosystems}

In just over a decade, two major ice shelves have collapsed on the eastern side of the Antarctic peninsula, uncovering a part of the sea floor that had not seen sunlight for several thousand years. A ten-week expedition that ended in late January has shed light on the biology of these waters, and has recovered samples of some 1,000 species from the region, several of which may be new to science.

"This is one of the first opportunities to see what will happen when climate change alters the conditions in the polar seas," says Jesse Ausubel, programme director at the Alfred P. Sloan Foundation in New York. The foundation is funding the Census of Antarctic Marine Life, an initiative for International Polar Year that

has 13 voyages scheduled.
From the German research vessel Polarstern, around 50 marine biologists from 14 countries used various approaches, including a remotely operated vehicle equipped with a camera, to scour the depths and trawl for samples. They surveyed an area of seabed roughly the size of Jamaica beneath what used to be the Larsen A and $B$ ice shelves, to a depth of 850 metres.

The biologists had two main aims: to discover what kinds of creatures live beneath ice shelves, and to track what happens to those communities once the ice disappears. Unexpected inhabitants of the relatively shallow waters were species more commonly found at greater depth.

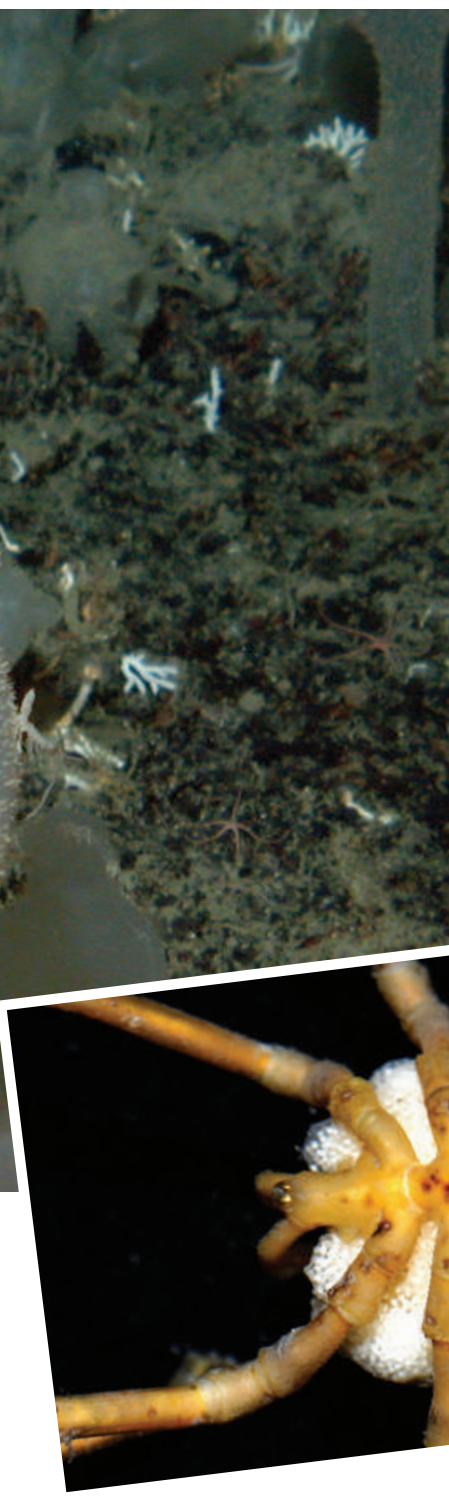

"We found a species of sea urchin that has previously been found only at depths of 2,000 to 3,000 metres off Peru," says Gauthier Chappelle, the expedition's outreach officer and a biologist at the Brussels-based International Polar Foundation. Presumably, such species are better able to adapt to conditions where resources are scarce, as they would have been under the ice.

Another find was juvenile forms of glass sponges in the Larsen A region; the Larsen A ice shelf collapsed 12 years ago, whereas the Larsen $B$ region opened up only 5 years ago. Glass sponges take hundreds of years to mature into adults, but are key members of Antarctic marine ecosystems,
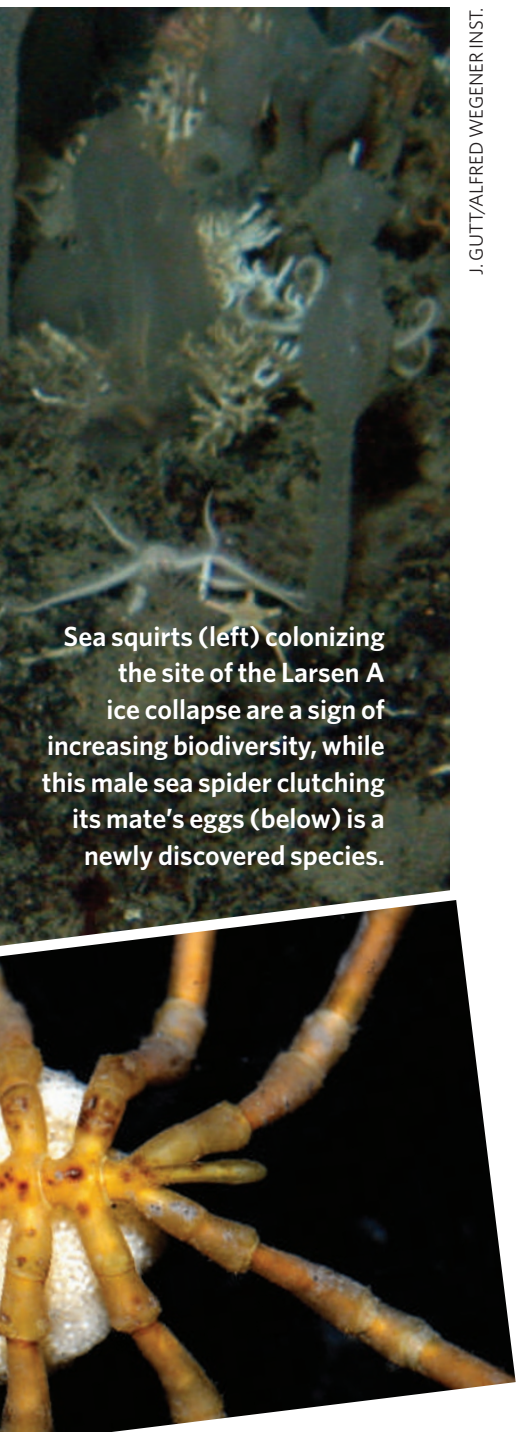

as they provide habitats for other species. "It seems like the system is shifting towards supporting the rich communities found in other parts of the Antarctic," says Julian Gutt, a marine ecologist at the Alfred Wegener Institute for Polar and Marine Research in Bremerhaven,

Germany, and chief scientist on the Polarstern expedition.

It would probably take between 1,000 and 5,000 years for the region to mature into the kind of community typical of Antarctic coastal regions, says Gutt. And future climate change could result in soils from the coast degrading the crystal-clear waters and potentially blocking any further succession to a rich community of Antarctic filter-feeders. 


\section{Federal agency rescinds primate stem-cell patents}

Three key stem-cell patents have been revoked by the US Patent and Trademark Office. Scientists have complained that the patents, held by the Wisconsin Alumni Research Foundation (WARF), are so broad that they impeded US research.

The patents were granted between 1998 and 2006, but last July several nonprofit groups requested that they be re-examined, arguing that the work described in the patents was not sufficiently novel to deserve protection. The patents claim to cover primate embryonic stem cells - including human embryonic stem cells - derived by any means. The patent office agreed, on reconsideration, that the work was not novel enough to deserve a patent.

WARF has two months to contest the decision, and could then initiate a lengthy appeals process.

\section{Nobel laureate named as NASA chief scientist}

NASA's science directorate has been boosted by the appointment of astronomer John Mather as the agency's chief scientist.

Formerly a somewhat isolated position, the chief scientist will now have his own staff and work closely with the new associate administrator for space science, planetary scientist Alan Stern. Mather shared the 2006 Nobel Prize in Physics for work to probe the cosmic microwave background, the relic radiation left over from the Big Bang.

But the news is mixed for the agency. Last week, some members of Congress moved towards ousting NASA's inspector-general, Robert Cobb. His position is meant to oversee the agency from an independent standpoint, but several Congressmen charge that Cobb was too close to a former agency chief to perform his duties properly.
An independent government committee last week passed a report to the House Committee on Science and Technology alleging that Cobb had misused his authority and created a hostile work environment. Several lawmakers have asked President George W. Bush to fire Cobb and may hold Congressional hearings on the matter. Cobb has not responded to the allegations.

\section{Arctic sea-ice cover reaches near-record low}

This year, the extent of winter sea ice in the Arctic came close to breaking the record for being the smallest ever.

On 4 April, scientists at the National Snow and Ice Data Center in Boulder, Colorado, announced that the maximum sea-ice cover last month was 14.7 million square kilometres. The record was set in March 2006, when the Arctic was covered by just 14.5 million square kilometres. This finding is consistent with the marked trend of sea-ice shrinkage and thinning that has been observed in recent decades.

NASA, meanwhile, reported last week that less ice may be persisting from year to year in the Arctic, so less is available to replenish the perennial pack ice each winter. A study by Ron Kwok, of the Jet Propulsion Laboratory in Pasadena, California, found that only $4 \%$ of the seasonal ice that formed in the winter of 2004-05 survived the summer melt and helped build up the perennial ice in the winter of 2005-06.

\section{UK report calls for change to stem-cell rules}

British politicians have criticized their government for proposing a ban on the creation of 'chimaeric' embryos, made from human DNA inserted into an animal egg. The Select Committee on Science and Technology, which is drawn from all the

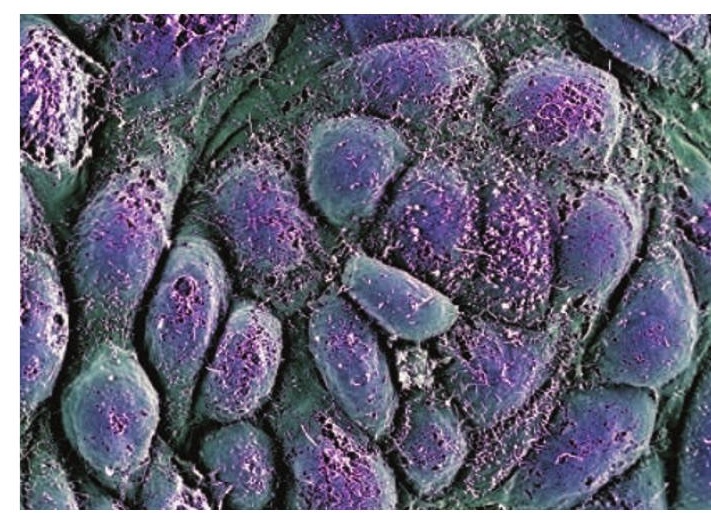

The creation of human stem-cell lines from 'chimaeric' embryos is controversial.

major parties, released a report on 5 April calling for a 'permissive' set of rules to be put in place that would allow the Human Fertilisation and Embryology Authority more freedom to adjudicate on the scientific merit of new embryological procedures.

The committee hopes the government will change the rules when it releases a draft bill next month. Only that would end the limbo for researchers at King's College London and the University of Newcastle, both of which have applied for licences to create chimaeric embryos to generate human stem-cell lines.

\section{University decides not to investigate smoking study}

Officials at the University of California have decided not to examine a controversial 2003 research article disputing the dangers of second-hand smoke.

In recent months, questions had been raised about whether the article, published in the British Medical Journal, involved scientific misconduct because it relied on purportedly faulty smoke-exposure data (see Nature 446, 242; 2007).

Epidemiologist James Enstrom of the University of California, Los Angeles, (UCLA) was the lead author of the article (J. E. Enstrom and G. C. Kabat Br. Med. J. 326, 1057; 2003), which reported that spouses of smokers were no more likely to develop lung cancer or heart disease than were spouses of non-smokers. Enstrom denied any impropriety.

Late last month, UCLA officials reviewed concerns raised by the American Cancer Society about Enstrom's article, and decided that the allegations were not worth a formal inquiry or investigation.

\section{Correction}

In our News story "Letting the light in on

Antarctic ecosystems" (Nature 446, 9; 2007),

the credit for the photo of the sea spider was

inadvertently omitted. The picture should have been credited to P. J. López, University of Seville/ Climant-Ecoantha. 